\title{
PERBANDINGAN MODEL JARINGAN SYARAF TIRUAN DENGAN ALGORITMA LEVENBERG-MARQUADT DAN POWELL-BEALE CONJUGATE GRADIENTPADA KECEPATAN ANGIN RATA-RATA DI KOTA SEMARANG
}

\author{
Dwi Ispriyanti ${ }^{1}$, Alan Prahutama ${ }^{2}$ Tarno $^{3}$, Budi Warsisto ${ }^{4}$, Hasbi Yasin ${ }^{5}$, \\ Pandu Anggara 6 \\ 1,2,3,4,5Staff Pengajar Departemen Statistika FSM Universitas Diponegoro \\ ${ }^{6}$ Mahasiswa Departemen Statistika FSM Universitas Diponegoro \\ Email: dwiispriyanti@yahoo.com
}

\begin{abstract}
Wind is one of the most important weather components. Wind is defined as the dynamics of horizontal air mass displacement measured in two parameters, namely speed and direction. Wind speed and direction depend on the air pressure conditions around the place. High wind speed intensity can cause high sea water waves. To estimate wind speed intensity required a study of wind speed prediction. One of method that can be used is Artificial Neural Network (ANN). In ANN there are several models, one of which is backpropagation. Thepurpose of this researchis to compare between backpropagation model with Levenberg-Marquadt and Powell-Beale Conjugate Gradient algorithms. The results of this researchshowing that Powell-Beale Conjugate Gradient better than Levenberg-Marquadtalgorithms. The best model architecture obtained is a network with two input layer neurons, six hidden layer neurons, and one output layer neuron. The activation function used are the logistic sigmoid in the hidden layer and linear in the output layer. MAPE value based on the chosen model is $0,0136 \%$ in training process and $0,0088 \%$ in testing process.
\end{abstract}

Keywords: Wind, Artificial Neural Network (ANN), Backpropagation,LevenbergMarquadt, Powell-Beale Conjugate Gradient, Neuron, MAPE

\section{PENDAHULUAN}

Angin merupakan salah satu komponen cuaca dalam kehidupan sehari-hari. Menurut [6], angin diartikan sebagai dinamika perpindahan massa udara secara mendatar (horizontal) yang diukur dalam dua parameter, yaitu kecepatan dan arah.Kecepatan dan arah angin bergantung pada kondisi tekanan udara di sekitar tempat tersebut.

Menurut [4], kecepatan angin yang melebihi $40 \mathrm{~km} / \mathrm{jam}$ dapat menyebabkan bencana, seperti nelayan yang tidak dapat melaut karena gelombang air laut yang tinggi.Besar kecilnya kecepatan angin di kota Semarang menjadi hal yang perlu dipertimbangkan mengingat kota Semarang berada di daerah pesisir Laut Jawa. Oleh karena itu, perlu dilakukan suatu penelitian mengenai kecepatan angin. Penelitian mengenai kecepatan angin dapat menggunakan Artificial Neural Network (ANN).

Artificial Neural Network (ANN) merupakan sistem pemroses informasi yang memiliki karakteristik mirip dengan jaringan syaraf pada makhluk hidup [1]. Metode Neural Network (NN) memiliki beberapa model, salah satunya adalah model backpropagation. Model backpropagation bertujuan untuk melatih suatu jaringan sehingga diperoleh bobot-bobot optimal yang meminimumkan error. Istilah 
backpropagation berhubungan dengan metode untuk perhitungan gradien fungsi error yang berkaitan dengan bobotbobot untuk suatu jaringan feedforward. Pelatihan menggunakan backpropagation meliputi tiga tahap, yaitu umpan maju (feedforward), perhitungan error, dan penyesuaian bobot [7].

Pada penelitian ini, proses pelatihan untuk menentukan bobot-bobot koneksi pada jaringan pelatihanbackpropagation digunakan algoritma LevenbergMarquadt dan Powell-Beale Conjugate Gradient dengan bantuan program Matlab R2009a.

\section{METODE PENELITIAN}

\section{Sumber Data dan Variabel Penelitian}

Data yang digunakan dalam penelitian ini adalah data sekunder yang bersumber dari Badan Meteorologi Klimatologi dan Geofisika Semarang. Data tersebut merupakan data kecepatan angin ratarata diKota Semarang dari periode 1 Januari 2016 sampai dengan 31 Agustus 2017 sejumlah 609 data.

Variabel yang digunakan dalam penelitian ini adalah data kecepatan angin rata-rata diKota Semarang dari periode 1 Januari 2016 sampai dengan 31 Agustus 2017 sejumlah 609 data. Data tersebut dibagi menjadi dua,yaitu data training dan testing. Data tersebut diidentifikasi menggunakan plot Partial Autocorrelation Function (PACF) sebagai penentuan variabel input.

\section{Tahapan Analisis Data}

1. Menyiapkan data kecepatan angin rata-rata hariandi Kota Semarang.

2. Menentukan variabel input melalui plot PACF.

3. Membagi data menjadi dua, yaitu data training dan testing.

4. Menentukan jumlah neuron lapisan tersembunyi dari masing-masing algoritma Levenberg-Marquadt dan Powell-Beale Conjugate Gradient.
5. Membandingkan nilai MAPE training dan testing dari masingmasing algoritma kemudian dipilih yang terbaik (terkecil) antara algoritma Levenberg-Marquadt dan Powell-Beale Conjugate Gradient.

6. Menentukan bobot awal.

7. Melakukan inisialisasi parameter (max epoch, learning rate, goal).

8. Melakukan proses training dan testing.

9. Lakukan secara iteratif dengan pemilihan nilai MAPE yang terkecil dari masing-masing algoritma.

10. Menentukan bobot akhir.

11. Memperoleh model jaringanbackpropagation terbaik.

\section{HASIL DAN PEMBAHASAN}

\section{Penentuan Variabel Input}

Penentuan variabel input dapat dilakukan dengan melihat lag-lag yang signifikan pada plot PACF dari data kecepatan angin rata-rata. Jika ada garis yang melewati selang kepercayaan pada plot PACF maka lag tersebut dianggap signifikan. Pada penelitian ini, lag yang signifikan adalah lag 1 dan lag 3 sehingga variabel input yang digunakan adalah $x_{t}$ dipengaruhi oleh $x_{t-1}$ dan $x_{t-3}$. Hal tersebut dapat ditunjukkan pada Gambar 1.

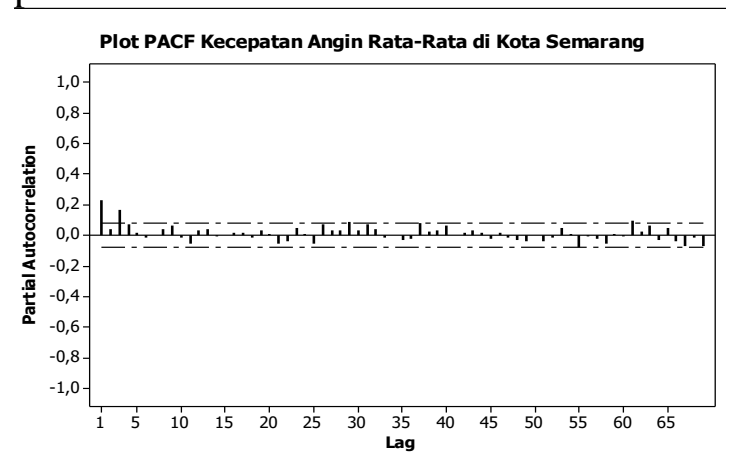

Gambar 1. Plot PACF Kecepatan Angin RataRata

\section{Pembagian Data}

Data yang digunakan untuk pemodelan jaringan backpropagation menggunakan algoritma Levenberg- 
Marquadt dan Powell-Beale Conjugate Gradient dibagi menjadi dua, yaitu data training dan testing. Pembagian data pada penelitian ini menggunakan $70 \%$ untuk data training dan 30\% untuk data testing. Oleh karena itu, diperoleh data training sebanyak 424 data dan data testing sebanyak 182 data.

\section{Penentuan Jumlah Neuron Lapisan Tersembunyi}

\section{Penentuan dengan Algoritma Levenberg-Marquadt \\ Untuk membangun jaringan} backpropagation menggunakan algoritma Levenberg-Marquadtdapat menggunakan perintah newff pada Matlab sebagai berikut:

1], \{'logsig'

'purelin'\},' trainlm');

Pada perintah tersebut, diulang sebanyak 10 kali dengan cara mencoba neuron lapisan tersembunyi mulai dari 1 sampai dengan 10 neuron. Hasil perhitungannya sebagai berikut:

Tabel 1. Nilai MAPE dari Algoritma Levenberg-

\begin{tabular}{c|c|c}
\multicolumn{3}{c}{ Marquadt } \\
\hline Neuron & MAPE training & MAPE testing \\
\hline 1 & 0,0161 & 0,0503 \\
2 & 0,0146 & 0,044 \\
3 & 0,0125 & 0,0618 \\
4 & 0,0123 & 0,0567 \\
$\mathbf{5}$ & $\mathbf{0 , 0 1 2}$ & $\mathbf{0 , 0 3 0 5}$ \\
6 & 0,012 & 0,0259 \\
7 & 0,0118 & 0,03 \\
8 & 0,0117 & 0,0456 \\
9 & 0,0114 & 0,0354 \\
10 & 0,0114 & 0,035 \\
\hline
\end{tabular}

Pada Tabel 1, diperoleh nilai MAPE training dan testing terkecil sebesar $0,012 \%$ dan $0,0305 \%$. Nilai tersebut berada pada 5 neuron pada lapisan tersembunyi (hidden layer) dan 1 lapisan output. Fungsi aktivasi yang digunakan pada lapisan tersembunyi adalah logsig (sigmoid biner) dan lapisan output adalah purelin (linear).

\section{Penentuan dengan Algoritma Powell-Beale Conjugate Gradient}

Untuk membangun jaringan backpropagation menggunakan algoritma Powell-Beale Conjugate Gradient dapat menggunakan perintah newff pada Matlab, yaitu:

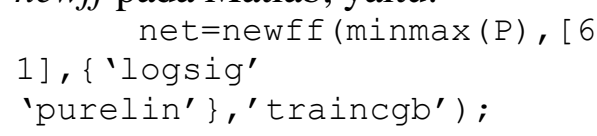

Pada perintah tersebut, diulang sebanyak 10 kali dengan cara mencoba neuron lapisan tersembunyi mulai dari 1 sampai dengan 10 neuron. Hasil perhitungannya sebagai berikut:

Tabel 2. Nilai MAPE dari Algoritma PowellBeale Conjugate Gradient

\begin{tabular}{c|c|c}
\multicolumn{3}{|c}{ Beale Conjugate Gradient } \\
\hline Neuron & MAPE training & MAPE testing \\
\hline 1 & 0,0161 & 0,0503 \\
2 & 0,0157 & 0,0477 \\
3 & 0,0125 & 0,0572 \\
4 & 0,013 & 0,034 \\
5 & 0,012 & 0,0766 \\
$\mathbf{6}$ & $\mathbf{0 , 0 1 3 6}$ & $\mathbf{0 , 0 0 8 8}$ \\
7 & 0,0122 & 0,0456 \\
8 & 0,012 & 0,0431 \\
9 & 0,0119 & 0,0443 \\
10 & 0,0116 & 0,0266 \\
\hline
\end{tabular}

Pada Tabel 2, diperoleh nilai MAPE training dan testing terkecil sebesar $0,0136 \%$ dan $0,0088 \%$. Nilai tersebut berada pada 6 neuron pada lapisan tersembunyi (hidden layer) dan 1 lapisan output. Fungsi aktivasi yang digunakan pada lapisan tersembunyi adalah logsig (sigmoid biner) dan lapisan output adalah purelin (linear).

Berdasarkan nilai MAPE yang dihasilkan, algoritma Powell-Beale Conjugate Gradient menghasilkan nilai yang lebih baik daripada LevenbergMarquadt sehingga dipilih algoritma Powell-Beale Conjugate Gradient sebagai dasar pembentukan model jaringan backpropagarion dengan 6 neuron lapisan tersembunyi dan 1 lapisan output menggunakan fungsi aktivasi sigmoid biner dan linear. 


\section{a. Penentuan Bobot Awal dan Inisialisasi Parameter}

Tahap awal dilakukan penentuan bobot awal dengan menggunakan software Matlab. Dalam menentukan bobot awal akan menghasilkan bobot dari lapisan inputdan bias ke lapisan tersembunyi serta bobot dari lapisan tersembunyi dan bias ke lapisan output dengan perintah sebagai berikut:

Bobot_Awal_Input_Hidden=net. IW $\{1$, 1\}

Bobot_Awal Bias Hidden=net.b $\{1,1\}$ Bobot_Awal_Hidden_Output $=$ net. $\operatorname{LW}\{2$ , 1$\}$

Bobot Awal Bias Output=net.b $\{2,1\}$

Penentuan parameter pembelajaran yang digunakan dalam pelatihan jaringan dengan algortimaPowell-Beale Conjugate Gradient backpropagation dengan net.trainParam untuk memperbaiki bobot dengan perintah sebagai berikut:

$$
\begin{aligned}
& \text { net.trainParam. epochs }=1000 ; \\
& \text { net.trainParam.goal=1e-3; } \\
& \text { net.trainParam. } 1 r=0.1 ;
\end{aligned}
$$

Jaringan yang telah terbentuk dapat dilatih dengan perintah sebagai berikut:

$$
\text { net=train (net, } \mathrm{P}, \mathrm{T} \text { ); }
$$

\section{b. Proses Training}

Proses training pada pelatihan jaringan dilakukan dengan algoritma Powell-Beale Conjugate Gradient backpropagation. Proses tersebut menghasilkan nilai MAPE sebesar $0,0136 \%$, artinya model jaringan yang terbentuk sangat baik.

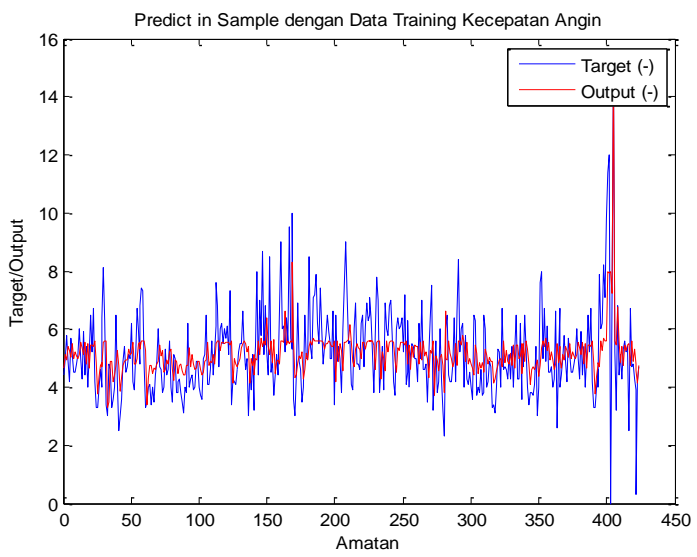

Gambar 2. Prediksi Data Target dengan Output Proses Training
Berdasarkan Gambar 2, dapat dilihat bahwa pelatihan jaringan telah memberikan hasil prediksi yang cukup akurat yang ditunjukkan dengan kedekatan pola output yang disimbolkan garis merah dengan data target yang disimbolkan garis biru.

\section{c. Penentuan Bobot Akhir}

Setelah proses training berhenti maka akan diperoleh bobot akhir. Penentuan bobot akhir yang diperoleh dari pelatihan jaringan dilakukan dengan perintah sebagai berikut:

Bobot_Akhir_Input_Hidden=net. IW $\{1$ $, 1\}$

Bobot_Akhir_Bias_Hidden=net.b $\{1,1$ \}

Bobot_Akhir_Hidden_Output $=$ net. $L W\{$ $2,1\}$

Bobot Akhir Bias_output=net.b $\{2,1$ \}

\section{d. Proses Testing}

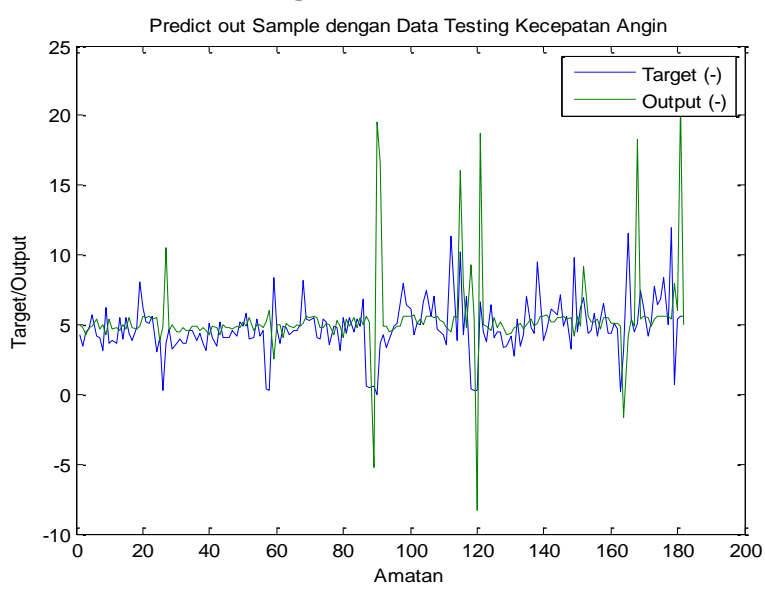

Gambar 3. Prediksi Data Target dengan Output Proses Testing

Berdasarkan Gambar 2, dapat dilihat bahwa proses testing telah memberikan hasil prediksi yang cukup akurat yang ditunjukkan dengan kedekatan pola output yang disimbolkan garis hijau dengan data target yang disimbolkan garis biru dengan nilai MAPE sebesar $0,0088 \%$.

\section{e. Penentuan Model Jaringan Terbaik}

Arsitektur model terbaik menggunakan jaringan backpropagation dengan algoritma Powell-Beale Conjugate Gradient yang dibangun dari 
6 neuron pada lapisan tersembunyi, 2 lapisan input dari $x_{t-1}$ dan $x_{t-3}$,serta 1 lapisan output. Fungsi aktivasi yang digunakan pada lapisan tersembunyi adalah sigmoid biner dan lapisan output adalah linear, dengan model yang diperoleh sebagai berikut:

$y_{k}=w_{k 0}+\sum_{j=1}^{6} w_{k j}\left(\frac{1}{1+e^{-\left(v_{j 0}+\sum_{i=1} x_{i} v_{j i}\right)}}\right)$

dengan

$w_{k 0}$ : bobot bias pada lapisan tersembunyi ke lapisan output

$w_{k j} \quad$ : bobot lapisan tersembunyi ke-j

ke lapisan output

$v_{j 0} \quad$ : bobot bias pada lapisan input ke lapisan tersembunyi ke- $j$

$v_{j i} \quad$ : bobot bias lapisan input ke lapisan tersembunyi ke- $j$

$x_{i} \quad$ : variabel input ke- $i$

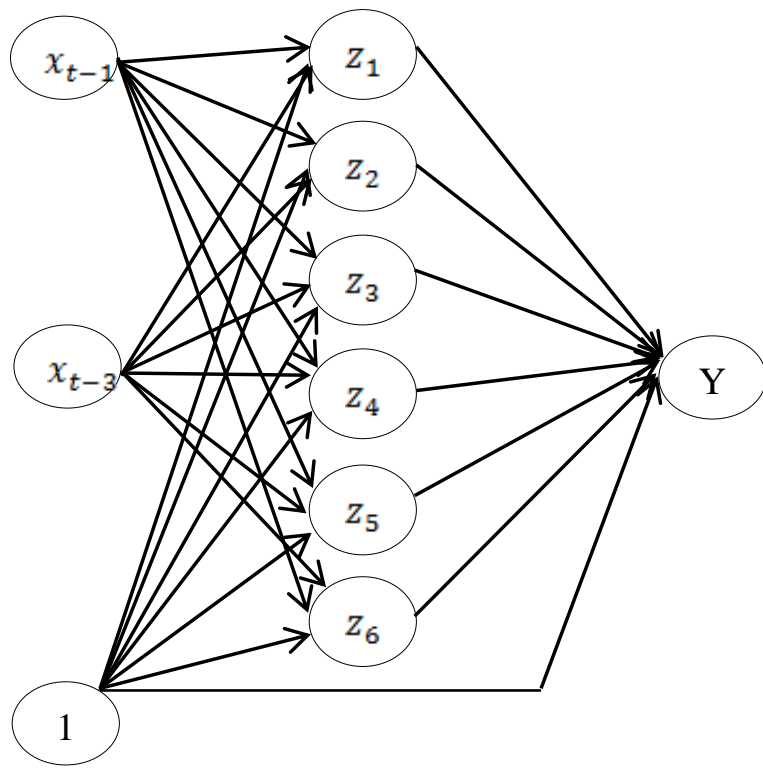

Gambar 4. Arsitektur Model Jaringan Syaraf Tiruan

Prediksi kecepatan angin di kota Semarang dengan model backpropagationmenggunakan bobot akhir yang diperoleh dari model terbaik. Model terbaik dibangun dari 6 neuron pada lapisan tersembunyi dengan 2 lapisan input dari $x_{t-1}$ dan $x_{t-3}$, serta 1 lapisan output. Sebagai contoh, perhitungan luaran secara manual dilakukan pada data testing periode 1Maret 2017. Data input yang digunakan adalah $x_{t-1}=4,3$ dan $x_{t-3}=4,2$. Berikut adalah perhitungan prediksi pada data testing periode 1 Juli 2017 dengan $x_{t-1}=4,3$ dan $x_{t-3}=4,2$.

Operasi luaran lapisan input ke-j ke lapisan tersembunyi sebagai berikut:

$z_{-} i n_{j}=v_{j 0}+\sum_{i=1} x_{i} v_{j i}$

Untuk $x_{t-1}=4,3$

$z_{-}$in $_{1}=-9,8141+4,3 \times 0,0507=-9,5961$

$z_{-} i n_{2}=-11,1220+4,3 \times(-5,2630)=-33,7529$

$z_{-}$in $_{3}=-5,9500+4,3 \times(-1,8088)=-13,7278$

$z_{-}$in $_{4}=-56,1543+4,3 \times 8,3637=-20,1904$

$z_{-}$in $_{5}=-7,3180+4,3 \times(-0,9114)=-11,2370$

$z_{-} i n_{6}=2,3097+4,3 \times 4,2060=20,3955$

Untuk $x_{t-3}=0,3$

$z_{-}$in $_{1}=-9,8141+4,2 \times(-0,3333)=-11,2140$

$z_{-}$in $_{2}=-11,1220+4,2 \times 0,3199=-9,7784$

$z_{-}$in $_{3}=-5,9500+4,2 \times 0,6806=-3,0915$

$z_{-}$in $_{4}=-56,1543+4,2 \times 19,0759=23,9645$

$z_{-} i n_{5}=-7,3180+4,2 \times 1,5581=-0,7740$

$z_{-} i_{6}=2,3097+4,2 \times 5,8280=26,7873$

Dengan menggunakan fungsi aktivasi sigmoid biner pada lapisan tersembunyi diperoleh:

$z_{j}=f\left(z_{-} i n_{j}\right)=\frac{1}{1+e^{-z_{-} i n_{j}}}$

Untuk $x_{t-1}=4,3$

$z_{1}=f(-9,5961)=\frac{1}{1+e^{9,5961}}=0,0001$

$z_{2}=f(-33,7529)=\frac{1}{1+e^{33,7529}}=0,0000$

$z_{3}=f(-13,7278)=\frac{1}{1+e^{13,7278}}=0,0000$

$z_{4}=f(-20,1904)=\frac{1}{1+e^{20,1904}}=0,0000$

$z_{5}=f(-11,2370)=\frac{1}{1+e^{11,2370}}=0,0000$

$z_{6}=f(20,3955)=\frac{1}{1+e^{-20,3955}}=1,0000$

Untuk $x_{t-3}=4,2$ 
$z_{1}=f(-11,2140)=\frac{1}{1+e^{11,2140}}=0,0000$

$z_{2}=f(-9,7784)=\frac{1}{1+e^{9,7784}}=0,0001$

$z_{3}=f(-3,0915)=\frac{1}{1+e^{3,0915}}=0,0435$

$z_{4}=f(23,9645)=\frac{1}{1+e^{-23,9645}}=1,0000$

$z_{5}=f(-0,7740)=\frac{1}{1+e^{0,7740}}=0,3156$

$z_{6}=f(26,7873)=\frac{1}{1+e^{-26,7873}}=1,0000$

Dilanjutkan menggunakan operasi luaran lapisan tersembunyi ke-j ke lapisan output:

$$
\begin{aligned}
y_{k}= & w_{k 0}+\sum_{j=1}^{6} w_{k j}\left(\frac{1}{1+e^{-\left(v_{j 0}+\sum_{i=1} x_{i} v_{j i l}\right)}}\right) \\
y_{1}= & -0,1281+(0,6195 \times(0,0001+0)+ \\
& 12,4994 \times(0+0,0001)+(-33,8019) \times \\
& (0+0,0435)+1,5931 \times(0+1)+ \\
& 12,4661 \times(0+0,3156)+0,4151 \times(1+1) \\
y_{1}= & 4,7616
\end{aligned}
$$

Dari perhitungan di atas dapat disimpulkan bahwa hasil prediksi kecepatan angin di kota Semarang menggunakan model backpropagation dengan algoritma Powell-Beale Conjugate Gradient yang dibangun dari 6 neuron pada lapisan tersembunyi, 2 lapisan input dari $x_{t-1}$ dan $x_{t-3}$, serta 1 lapisan outputserta fungsi aktivasi sigmoid biner dan linear menghasilkan nilai sebesar 4,7616.

\section{KESIMPULAN}

Berdasarkan analisis yang telah dilakukan, diperoleh kesimpulan sebagai berikut:

1. Pelatihan jaringan syaraf tiruan menggunakan backpropagation dengan algoritma LevenbergMarquadtmenghasilkan nilai MAPE training dan testing sebesar $0,012 \%$ dan $0,0305 \%$ sedangkan algoritma Powell-Beale Conjugate Gradient menghasilkan nilai
MAPE training dan testing sebesar $0,0136 \%$ dan $0,0088 \%$. Oleh karena itu, algoritma Powell-Beale Conjugate Gradient lebih baik daripada Levenberg-Marquadt.

2. Arsitektur model terbaik dibentuk menggunakan algoritma PowellBeale Conjugate Gradient yang dibangun dari 6 neuron pada lapisan tersembunyi, 2 lapisan input dari $x_{t-1}$ dan $x_{t-3}$, serta 1 lapisan output dengan fungsi aktivasi pada lapisan tersembunyi adalah logistic sigmoid dan lapisan output adalah linear sebagai berikut:

$$
y_{k}=w_{k 0}+\sum_{j=1}^{6} w_{k j}\left(\frac{1}{1+e^{-\left(v_{j 0}+\sum_{i=1} x_{i} v_{j i}\right)}}\right)
$$

\section{DAFTAR PUSTAKA}

[1] Fausset, L. 1994. Fundamentals of Neural Networks: Architectures, Algorithms, and Applications. New Jersey: Prentice-Hall Inc.

[2] Haykin, S. 1999. Neural Networks a Comprehensive Foundation. New Jersey: Prentice-Hall Inc.

[3] Kusumadewi, S. 2004. Membangun Jaringan Syaraf Tiruan Menggunakan MATLAB \& Excel Link. Yogyakarta: Graha Ilmu.

[4] Nurvitasari, Y dan Irhamah. 2012. Pendekatan Fungsi Transfer Sebagai Input Adaptive NeuroFuzzy Inference System (ANFIS) dalam Peramalan Kecepatan Angin Rata-Rata Harian di Sumenep. Jurnal Sains dan Seni Institut Teknologi Sepuluh November Vol. 1 No. 1

[5] Siang, J.J. 2005. Jaringan Syaraf Tiruan dan Pemrogramannya Menggunakan Matlab. Yogyakarta: Penerbit Andi.

[6] Turyanti, A dan Effendy, S. 2006. Meteorologi. Bogor: Institut Pertanian Bogor 
Statistika, Vol. 8, No. 2, November 2020

[7] Warsito, B. 2009. Kapita Selekta

Statistika Neural Neural

Network. Semarang:BP UNDIP. 